\title{
IMPLICATIONS OF WORIKFORCE DIVERSITY ON PERFORMANCE AND ORGANISATIONAL EFFECTIVENESS IN IT INDUSTRY - A CONCEPTUAL STUDY
}

KEY WORDS: Workforce

Diversity, Organisation

performance, IT industry.

\section{Dr. Sukanya R}

\section{Manjula R*}

Assistant Professor, Department of Commerce, Karnataka State Open University.

Research Scholar, Department of Commerce, Karnataka State Open University. *Corresponding Author

Organisation performance and its effectiveness always depend on the workforce incubated by the employers. Workforce diversity plays a major role in employee's career and professional performance which needs to be focused properly in order to manage it efficiently and effectively as it directly deals with overall organisational performance. As per the previous research studies, workforce is inclusive of morale, culture and employee engagement where industries inculcate the workforce culture wherein due to this the company performance fosters to industry standards. In the present situation, the diversity is highly recognised and it also serves as a resource for an organization which means in the global scenario, proving efficiency, increasing competency, attending the standards and benchmarks has become one of the biggest challenge for the industries for which the major attention has to be paid. Overall management of work culture is also a very important area to focus. In this regard, the present research focuses on the impact of workforce diversity on organisational performance and its effectiveness in IT industry which also throw lights on individual characteristics such as gender, age, education, knowledge and their thought process. This study has considered the performance and organisational effectiveness as dependent variables and workforce diversity as independent variable.To analyse the research data secondary source of data collection such as, journals, articles and online source has been considered from which the findings and conclusions are drawn.

\section{INTRODUCTION}

As India is regarded as a diversified country where people are from a range of different social and ethnic backgrounds and at different demographics which highlights that people from one place to another being differential group sets with various dimensions of diversity are joining together in their profession and career goals to prove themselves. Barak (2016) featured that workforce diversity has been as recognized, needs to be understood, tolerated, among individuals which exist. He also throws light on certain range of dissimilarities like age, class of people, gender, physical and intellectual capability, caste and race, financial and social status and religion they belong to. In addition to this he also explains that some similarities and dissimilarities defines the values and roles of Organisation and also speaks on professional and behavioural styles of the people employed therein.Elizabeth Foma (2014) exhibit that the various important elements are associated with workplace diversity there also exist the problems concerning workplace diversity, and the most important one is the challenges in managing of workplace diversity. Gomez and Bernet (2019) explained that diversity in workplace improves the performance which results in the higher revenues and other financial growth like increase in outcome, improved quality output accuracy and creativity.

Further they explains that any improvements in personal quality productivity is a opportunity to the organisation and team work spirit will develop to the core and this contributes towards the achievements of financial and organisational overall goals. And employee retention is one of the major tasks of the industry or organisation which demands the clinical research on workforce diversity and its dimensions.

\section{Statement of Problem:}

In the present scenario, the entire world including India is demanding new methods of diversity management techniques in the working environment which helps in increasing the morale of the employees, financial potentiality and high productivity. The stated diversities of the industry need major focus for increasing expertise skills and imbibing good behaviours and attitudes among the employees. Even in Case of human resource managers implementation of good workplace diversity has been a greater task to be competent in this digital world. The strategic management of human resources demands for industrial productivity and performance which also depicts the effectiveness of organizations.

\section{Review of Literature:}

Schoenfeldt, and Shaw, (1999) states that advanced diverse methods in the organisation creates coordinating working environment which develops a overall new working application which increase the morality of the individuals and also helps in the performance and productivity.

Easley, (2001) explains that the new world environment always demands for complete management of diversed environment will helps the industries to be in the new pace to cope up with upgraded, standardized and advanced development in working conditions.

Jeffery Sanchez-Burks and Michal E. Mor Barak(2005)is of opinion that the interpersonal relationship in the organisation especially in case of IT industry is an important aspect to be focused as the values and perceptions and other behaviour which is of major concern to focus.

Kulin Patel and AnuradhaSriram, (Oct 2010) in their article express that, the combined organisation's and business with their roles are in need of managing diversified workforce in a better ways and its methods. The different kind of cultures and comfort zones are major aspect which plays an important role in increased performance.

Tang, Zheng, \& Chen, (2017) states that the workforce diversity always contributes in the problem solving technique of the organisation where people are large in number with diversified behaviour where there is a need of managing many perceptions and different mindsets.

Hwang and Hopkins (2015) as per their research work they are of opinion that if the employees feel that they are part of the organisation the inclusiveness mindset will always results in job satisfaction and the also increases the loyalty of employees if they feel that they are not included in the organisation the performance will be low. This demands compulsory focus and management of the company. 
Muchiri and Ayoko (2013)The study tells that the diversity depends on the firm's decision if at all the firm thinks that it has to be taken care because of the various types of diversity existing in then the performance can be viewed from that perceptive and much of the employee behaviour in organisation is not based on the demographic diversity of their own but it might be of organisation behaviour alone.

\section{Research Gap:}

Most of the research studies focused on overall workforce diversity in case of organisation productivity and performance and further many research studies also focused on organisational performance and productivity in case of IT sectors. But after taking extensive literature review it has been found that the implications of the workforce diversity on IT industry performance and effectiveness is not been focused much taking its challenges into consideration. Therefore this research study focus on those aspects to observe deeply about the impact of the workforce diversity based on above said perspective view.

\section{Objectives of Study:}

a. To know the major workforce diversity that is associated with the working environment.

b. To know the focus of organisation on managing the workforce diversity.

c. To analyse the impact of workforce diversity on organisational performance and effectiveness.

\section{Research Methodology:}

The research has been conducted to know the impact of workforce diversity and challenges faced by human resources mangers in managing the performance and effectiveness of organisation with the consideration as a major focus during pandemic present scenario for which extensive reviews were made on the secondary sources such as books, journals, articles, newspapers and online sources even individual's opinions from IT sector were taken informally to gather data from whom first-hand information was gathered for making honest effort to conduct this research work.

\section{Analysis and Discussion:}

People in the organisation are diverse from their background and ethnicity and this is present in anywhere in the world. Workforce diversity is existed not only in culture, demographics and other similarities but also in perceptions, behaviours and prejudices of people. This has resulted in much more important aspect to focus in the organisation. In the IT industry its plays a major role in managing it as people are heterogeneous in nature in the present working environment.

Apart from this there are visible and invisible diversities. Visible diversities such as age, gender, race etcare easily noticeable but invisible diversities such as opinions, attitudes, perceptions and behaviours cannot be easily identified or rectified and which need major attention to pay in the industry.Human resources are the major asset and carry the competitive edge in the IT firms.

Human resources potentiality and their sustainable competitions plays major role in organisation performance and productivity.

Today's challenges to the executives of the IT firms are to identify the diversities of workforce and improve their potentiality to achieve financial growth. Diverse people have different perceptions which influence their behaviour patterns which have to be handled carefully and accurately. No attention or discriminations will lead to negative impact on the working environment. Therefore it is the duty of the human resource manager to carefully study the existing diversity in the firm in order to manage it as per the organisational requirement and also to increase the performance.

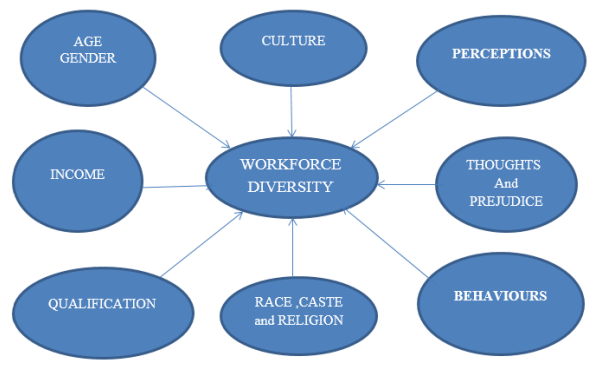

Figure: 1 Workforce diversity

The above figure (Figure: 1 work force diversity) shows that the workforce diversity carries various issues which is carried along with the people or employees wherever they go. The above mentioned diversities existing among all the employees are not so easy to tackle and manage but still it the major concern and one can view that managing few noticeable diversities may be quite easy but invisible diversities like behaviours, perceptions thoughts and prejudice is not easy to tackle as it varies from person to person and also from time to time which has its own pattern depending on the situations.

Further recent research has highlighted that the invisible diversities are like in depth level of diversity which impacts the working culture and now it has to be analyzed carefully for the purpose of bringing a common behaviour pattern to achieve the desired goals. Human resource is concerned with the people where it is unlike materials and machines as it a very sensitive aspect of organisation part. Human part is main part which takes every step ahead in the progress of the work in firms. In this regard organisation and human resources are mutually connected to satisfy each's need though the diversities indulged in between. So there is a need of focusing on both the objectives.

Match between the objectives of the organization with individual's goals results in achievement of pre-set objectives of the firms. So far we have discussed that whether work force diversity is exist in the present scenario and impacting the working environment and whether all diversities are there in the organisation or not and how it plays a major role. Now let us concentrate on its correlation with performance of individuals and its overall effectiveness in the organisation. In order to analyse this below Figure (Figure: 2 workforce diversity influencing employee performance and overall organisational effectiveness) has been considered as a framework.

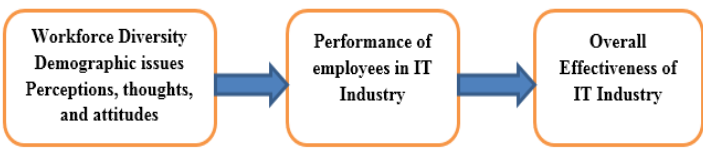

Figure: 2 Workforce diversity influencing employee performance and organisation effectiveness

Now let us look the aspect of win- win situation for both organisation and employees in IT firms. Whenever we speak about performance and productivity towards growth it is nothing but converting the available input into output. Here the input is the human resource in the firms and output is their performance. Considering this how both employees and organisation are satisfied? It is obvious that any economic position of the organisation depends on its effective performance and they also focus on efficiency which demands competency from the employees.

Various authors specify that when needs and wants are satisfied to the particular level then the question is what's next? To answer this now let us consider Maslow's need 
hierarchy theory which states that once the particular need is satisfied then it always focus on the next desire. By putting this application to the present study here the employees' growth changes and moves ahead as per their satisfaction of the requirement and even the organisation's case as well is that if their present goals are satisfied further they move on to the next objectives. All these is done to face the competitiveness in the economy this mutual relationship has created a bondage between the employer and employee to achieve their goals during life time.

For achieving the objectives the organisation should focus on how this can be achieved again managing all the diversities of employees. It is the task of the human resource managers to focus on each and every employee profile where they fit in the job , their background how they will perform and their quality of performance, their ethnicity how they consider the work and loyalty towards job, behaviour pattern which shows how their interrelationships in the working environment and organisation is present, perceptions they carry and prejudices with will influence their own performance and influence towards the organisational effectiveness. Therefore this proves that work diversity influences the employee performance and contributes towards the overall effectiveness of the organisation.

\section{Limitations of the Study:}

1. The analysis for the research is based on the information gathered through secondary sources.

2.The above study is limited to IT Industry only.

3 The study is limited Indian Context only.

\section{Conclusion:}

After taking the literature review, research gap was identified where research focus is on the work diversity of IT firm employees influencing their performance which in turn impacts on the overall effectiveness of the organisation. Based on this the objectives were also framed; accordingly it has been proved that the workforce diversity is associated with the performance of employees in the firms.

Further as per the reviews done for the study it is proved that the organisation is very much keen about the work diversity and its management in working environment and it has been observed that managing to handle the employees with the existing diversity has been considered as firms' challenge and taken seriously to implement good frameworks to manage it.

Based on the above factors the analyzing of the framework has also been considered wherein it explains that the workforce diversity has been observed as major aspect of IT firms and its influence on employees' performance is very much direct in nature, together this has impact on the organisational effectiveness.

Overall work diversity of organisation carries diverse aspects which are sensitive in nature and needs to be focused without neglecting and at same time, managing it will help organisation in improving its employees' performance and this in turn contributes towards organisational competitive growth, efficiency and effectiveness which has already been proved in the above conceptual analysis. Therefore the workforce diversity and its framework which is drawn for analysis of the present study hold good to share the factual views of the researcher.

\section{REFERENCES:}

1. Ankita Saxenaa of Anand Engg. College, Agra-Workforce Diversity: A Key to Improve Productivity-Symbiosis Institute of Management Studies Annual Research Conference(SIMSARC13)-Procedia Economics and Financel1 (2014)76-85.

2. Elizabeth Foma,University of Guam- Impact of Workplace Diversity: Review of Integra8.tive Business and Economics Research.Rev.Integr.Bus.Econ.Res. Vol3(1) 3

3. Kanza Tariq Khan ShaistaJabeen,-Impact of Workplace Diversity on Organizational Citizenship Behavior-19, Journal of Management and
Research (JMR) Volume 6(2): 2019- Investigating the Impact of Workplace Diversity on Organizational Citizenship Behavior: The Mediating Role of Inclusion.

4. Cynthia D.Fisher,Lyle F.Schoenfeldt,James B.Shaw-Human Resource Management by Cynthia D. Fisher, Lyle F. Schoenfeldt, James B. Shaw Houghton Mifflin Company, 1999 - Goal setting in personnel management.

5. Glenda Strachan, John Burgess and Anne Sullivan The University of Newcastle, NSWAffirmative Action or Managing Diversity-What is the Future of Equal Opportunity Policies in Organisations?https://core.ac.uk/ display/143869933.

6. Jeffery Sanchez-Burks and Michal E. MorBarak(2005)Chapter 9: Interpersonal Relationships in a GlobalWork Context (online)

7. Hwang and Hopkins (2015)A structural equation model of the effects of diversity characteristics and inclusion on organizational outcomes in the child welfare workforce Children and Youth Services Review -Volume 50, March 2015, Pages 44-52

8. Muchiri and Ayoko (2013)Linking demographic diversity to organisational outcomes: The moderating role of transformational leadership.The moderating role of transformational leadership. Leadership \& Organization Development Journal, 34(5), 384-406.

9. Gunjan. S, Workforce Diversity, Article shared by business management ideas

10. Outstanding business management ideas.

Websites:

- https://psycnet.apa.org/record/

- https://www.sciencedirect.com

http://webuser.bus.umich.edu/

https://core.ac.uk/download/

https://books.google.co.in/books/

https://www.sciencedirect.com/science/article/

https://www.yourarticlelibrary.com/

https://www.businessmanagementideas.com/ 